\title{
Achieving optimal micro-explosions in stable emulsions by adding water-soluble polymers
}

\author{
Cao $\mathrm{Liu}^{1}$, Tianchun $\mathrm{Xiao}^{2}$, Lingrui $\mathrm{Cui}^{3}$, Lian $\mathrm{CEN}^{1}$, Jinshan $\mathrm{XU}^{3}$, Peixun $\mathrm{Li}^{4}$, and Fahai \\ $\mathrm{Cao}^{1}$ \\ ${ }^{1}$ East China University of Science and Technology \\ ${ }^{2}$ University of Oxford \\ ${ }^{3}$ Affiliation not available \\ ${ }^{4}$ ISIS Pulsed Neutron and Muon Source
}

January 1, 2022

\begin{abstract}
The emulsified feedstock technique is to improve the performance of products by using the micro-explosion phenomenon of emulsion. However, an obstacle to some applications of this technology is the contradiction between emulsion stability and micro-explosion intensity. For the first time, adding water-soluble polymers was proposed to solve this problem. Two polymers of xanthan gum (XG) and nonionic polyacrylamide (NPAM) were investigated and the results show that micro-explosions have five forms. As one of these five forms, the intensity of optimal micro-explosion is three orders of magnitude higher than other forms, and adding $0.5 \%$ XG increases the probability of optimal micro-explosion from $0 \%$ to $60 \%$ due to the low surface activity, strong thickening and pseudoplasticity of XG solutions. By contrast, NPAM does not promote micro-explosion because of its strong surface activity. Finally, a new mechanism for micro-explosions related to surface tension, interfacial tension and viscosity is proposed.
\end{abstract}

\section{Achieving optimal micro-explosions in stable emulsions by adding water-soluble polymers}

Cao $\mathrm{Liu}^{1}$, Jun $\mathrm{Xu}^{1,2}$, Lingrui $\mathrm{Cui}^{1,2}$, Lian $\mathrm{Cen}^{1}$, Jinshan $\mathrm{Xu}^{3}$, Peixun $\mathrm{Li}^{4}$

Tiancun $\mathrm{Xiao}^{5 *}$, Fahai $\mathrm{Cao}^{1,2 *}$

${ }^{1}$ School of Chemical Engineering, East China University of Science and Technology, Shanghai 200237, China

${ }^{2}$ Engineering Research Center of Large Scale Reactor, East China University of Science and Technology, Shanghai 200237, China

${ }^{3}$ Sinopec Qilu Company, Zibo 255400, China

${ }^{4}$ ISIS Facility, Rutherford Appleton Laboratory, STFC, Didcot, OXON, OX11 0QX, UK

${ }^{5}$ Inorganic Chemistry Laboratory, Department of Chemistry, University of Oxford, Oxford OX1 3QR, UK

*Corresoindence:

Tiancun Xiao, Inorganic Chemistry Laboratory, Department of Chemistry, University of Oxford, Oxford OX1 3QR, UK, E-mail: xiao.tiancun@chem.ox.ac.uk (Tiancun Xiao)

Fahai Cao, School of Chemical Engineering, East China University of Science and Technology, Shanghai 200237, China; Engineering Research Center of Large Scale Reactor, East China University of Science and Technology, Shanghai 200237, China. Email: fhcao@ecust.edu.cn (Fahai Cao) 
Funding information: Sinopec Innovation Foundation (120022)

\begin{abstract}
The emulsified feedstock technique is to improve the performance of products by using the micro-explosion phenomenon of emulsion. However, an obstacle to some applications of this technology is the contradiction between emulsion stability and micro-explosion intensity. For the first time, adding water-soluble polymers was proposed to solve this problem. Two polymers of xanthan gum (XG) and nonionic polyacrylamide (NPAM) were investigated and the results show that micro-explosions have five forms. As one of these five forms, the intensity of optimal micro-explosion is three orders of magnitude higher than other forms, and adding $0.5 \%$ XG increases the probability of optimal micro-explosion from $0 \%$ to $60 \%$ due to the low surface activity, strong thickening and pseudoplasticity of XG solutions. By contrast, NPAM does not promote micro-explosion because of its strong surface activity. Finally, a new mechanism for micro-explosions related to surface tension, interfacial tension and viscosity is proposed.
\end{abstract}

Keywords : emulsion; micro-explosion; polymer additives; viscosity; surface tension

\title{
1 Introduction
}

Micro-explosion is a phenomenon, which is that the sudden explosive boiling of a small droplet splits the parent droplet into more sibling droplets, improving atomization efficiency and promoting mass and heat transfer. Good atomization effect plays an important role in flame spray pyrolysis (FSP), fluid catalytic cracking (FCC) and fuel combustion ${ }^{1-5}$. So, emulsified feedstock technique, which replaces the feedstock with water-in-oil (W/O) emulsions, is developed to try to use explosive boiling of lighter components (water) making the micro-explosion more intense ${ }^{2,6,7}$. Several studies have shown the potential of this emulsified feedstock technique in chemical production. ${ }^{8-11}$

Due to the great potential of micro-explosion application, a large number of researchers have sought to understand its mechanism and regular patterns by exploring and observing the micro-explosion phenomenon of single droplets ${ }^{12-14}$. It has been found that there are at least two different forms of micro-explosion in single droplet micro-explosion experiments, namely "micro-explosion" and "puff"12,15-20. In some studies, these two forms of micro-explosion are also called "optimal micro-explosion" and "non-optimal micro-explosion" respectively $6,7,21,22$. Optimal micro-explosion is a form of micro-explosion where the whole droplet is completely torn in 1 millisecond without any expansion process. It is hence regarded as the optimal form of micro-explosion as it yields the best atomization effect ${ }^{21,22}$.

In recent years, the research on optimal micro-explosion has attracted great attention. Importantly, a large number of studies have shown that the optimal micro-explosion is related to the concentration of surfactants and the particle size of the dispersed water phase, and a summary of these studies is shown in Table 1. As shown in Table 1, we find that there is almost no literature on optimal micro-explosion in emulsions with dispersed water phase particle size less than $2 \mu \mathrm{m}$. Some studies believe that this is because the necessary condition for optimal micro-explosion is to first undergo the coalescence of dispersed water phase $\mathrm{e}^{17,23-25}$.

On the other hand, due to Ostwald ripening mechanism, partial dissolution of the dispersed liquid phase caused by capillary pressure leads to mass transfer from small to large droplets ${ }^{26}$. This means that the smaller the particle size and the narrower the distribution of the dispersed water phase of the emulsion, the more stable it will be. However, as mentioned above, the micro-explosion intensity of $\mathrm{W} / \mathrm{O}$ emulsion with dispersed water phase particle size less than $2 \mu \mathrm{m}$ will be greatly reduced. In other words, this actually creates a contradiction between the stability of the emulsion and the intensity of the micro-explosion ${ }^{15}$. This contradiction is currently the main obstacle restricting the promotion and development of emulsified feedstock technique. For example, the application of emulsified bio-fuel oil in compression ignition engines is presently a hot topic ${ }^{27-30}$. However, the main factor limiting its application is not only cost, but also the poor stability of emulsion. Therefore, in order to solve the problem of poor stability of emulsified fuel, 
some scholars have studied the microemulsion based hybrid biofuels (MHBF) which is made of biofuel into microemulsion ${ }^{29}$. Microemulsion refers to the emulsion with the diameter of dispersed droplets between $5 \mathrm{~nm}-100 \mathrm{~nm}$. Different from traditional emulsion, microemulsion is a thermodynamically stable system ${ }^{31,32}$. However, due to the contradiction between the particle size of the dispersed water phase and the intensity of micro-explosion, there is poor micro-explosion effect for the microemulsion biofuel.

We note that there is a large amount of literature on the effect of water-soluble polymers as additives on pool boiling ${ }^{33-37}$. Athavale et al. ${ }^{34}$ showed that the high viscous drag at the dynamic vapor-liquid interface tends to suppress or retard the post-nucleation growth of vapor bubbles, which is detrimental to the pool boiling process. Moreover, the inhibition effect will disappear as heating surface temperature increases. Although pool boiling and micro-explosion are two different systems of study, they are both essentially boiling phenomena. Therefore, if this effect is applied to the micro-explosion process, it is possible to promote the optimal micro-explosion of stable emulsion.

The aim of this study is to resolve the contradiction between emulsion stability and micro-explosion intensity by adding a polymer in the aqueous phase of a stable emulsion with an appropriate amount of surfactant. In addition, the morphology of micro-explosion is further analyzed to find out the mechanism.

Table 1 Effect of surfactant concentration and particle size of dispersed water phase on microexplosion

\begin{tabular}{lllll}
\hline Type of oil $/ \%$ & Percentage of water $/ \%$ & Percentage of emulsifier $/ \%$ & HLB & Average particle size of dispersed water \\
\hline Diesel Oil & 30 & 3.0 & 2.0 & 1.2 \\
Diesel Oil & $10-30$ & Span80 / 1.0 & 4.3 & Unknown \\
Sunflower Oil & $30 \%$ & Span 83 / 0.15-1.0 & 3.7 & $3.5-10$ \\
Sunflower Oil & $25-30$, & Span83 / 2.5-10 & 3.7 & $2.56-17.39$ \\
N-hexadecane & 30 & Span80 / 0.5-3.5 & 4.3 & $4.13-4.46$ \\
N-hexadecane & 30 & Span80 / 4.0-5.0 & 4.3 & $4.18-4.22$ \\
Diesel Oil & 20 & Span80 / 3.0 & 4.3 & Unknown \\
Diesel Oil & $5-17.5$ & Span80 / 3.0 & 4.3 & Unknown \\
Diesel Oil & 10 & Span80 / 0.75 & 4.3 & 3.1 \\
Diesel Oil & $10-30$ & Span80 / 2-5 & 4.3 & $1.5-16$ \\
\hline
\end{tabular}

\section{Materials and methods}

\subsection{Preparation of polymer solutions}

Nonionic polyacrylamide (NPAM) and Xanthan gum (XG) are two kinds of water-soluble polymer thickeners commonly used in chemical production. In this study, NPAM (Rhawn Company, $\mathrm{M}_{\mathrm{W}}=12000 \mathrm{~kg} / \mathrm{mol}$ ) and Xanthan gum (Yuanye Biotechnology Company, $\mathrm{M}_{\mathrm{W}}=2600 \mathrm{~kg} / \mathrm{mol}$ ) were used as polymer additives to prepare $\mathrm{W} / \mathrm{O}$ emulsions to investigate their effects on micro-explosion. The chemical structures of NPAM and XG are shown in Figure 1a and Figure 1b respectively.

(a)

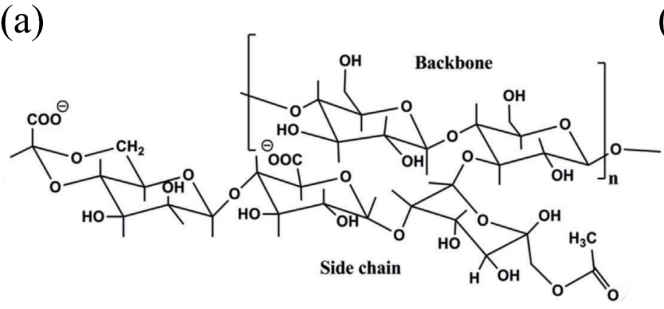

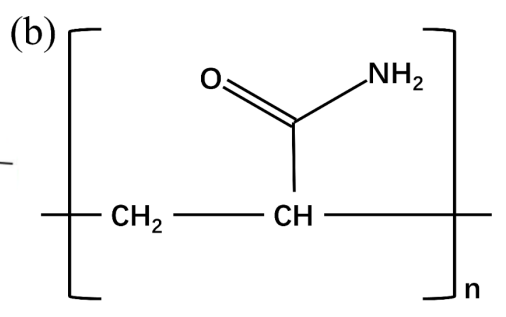




\section{Figure 1 Chemical structures of XG and NPAM (a)XG; (b)NPAM}

The solutions were prepared by dissolving precise quantities of XG and NPAM powder into deionized water, using an electronic balance with an accuracy of $\pm 0.1 \mathrm{mg}$. Because these water-soluble polymers are extremely hydrophilic, if water is added directly without adequate stirring, the outer layer absorbs water and expands into micelles, preventing water from entering the inner layer. Therefore, the beaker was first filled with deionized water and stirred at $400 \mathrm{rpm}$ on an electric stirrer with a three-bladed spiral paddle. Then, the polymer powder was slowly added while stirring until the polymer powder was completely added into the beaker. Finally, in order to ensure that the polymer powder is completely dissolved, it needs to be gently stirred at $200 \mathrm{rpm}$ for another 4 hours. The completely dissolved solution is transparent and has no suspended particulates.

\subsection{Preparation of $\mathrm{W} / \mathrm{O}$ emulsion fuels}

In this experiment, n-hexadecane was used as oil phase and polymer solution as water phase to prepare $\mathrm{W} / \mathrm{O}$ emulsion. Each time $80 \mathrm{~g}$ of n-hexadecane (Rhawn Company) was mixed with $2.0 \mathrm{~g}$ of surfactant Span 80 (Aladdin Biochemical Technology Company) under magnetic stirring until a clear solution was obtained. Afterwards $20 \mathrm{~g}$ of polymer solution was added drop by drop and the mixture was stirred with a homogenizer at $6000 \mathrm{rpm}$ for $15 \mathrm{~min}$. All the weighing process was performed using an electronic balance with an accuracy of $\pm 0.1 \mathrm{mg}$. Different kinds of emulsions were prepared by changing the addition type and amount of polymer, named S2.0, XG0.1, XG0.5, XG1.0, PAM0.01, PAM0.1 and PAM1.0 respectively, as shown in Table 2.

\section{Table 2 Composition of the emulsions}

\begin{tabular}{llllllll}
\hline & S2.0 & XG0.1 & XG0.5 & XG1.0 & PAM0.01 & PAM0.1 & PAM1.0 \\
\hline N-hexadecane/g & 80 & 80 & 80 & 80 & 80 & 80 & 80 \\
Deionized water/g & 20 & 20 & 20 & 20 & 20 & 20 & 20 \\
Span80/g & 2 & 2 & 2 & 2 & 2 & 2 & 2 \\
Type of additives & No additives & XG & XG & XG & NPAM & NPAM & NPAM \\
Concentration of polymer solution $[\mathrm{g} / \mathrm{dL}]$ & 0 & 0.1 & 0.5 & 1.0 & 0.01 & 0.1 & 1.0 \\
\hline
\end{tabular}

\subsection{Single droplet micro-explosion experiment}

In this study, the experimental device referred to the literature of Shiquan Shen et al. ${ }^{17}$, with added improvements was utilized for the optical imaging system. The schematic of experiment setup is shown in Figure 2. It mainly consists of a heating chamber, an optical imaging system, a high-speed photographic system, a synchronous triggering device and a data acquisition system.

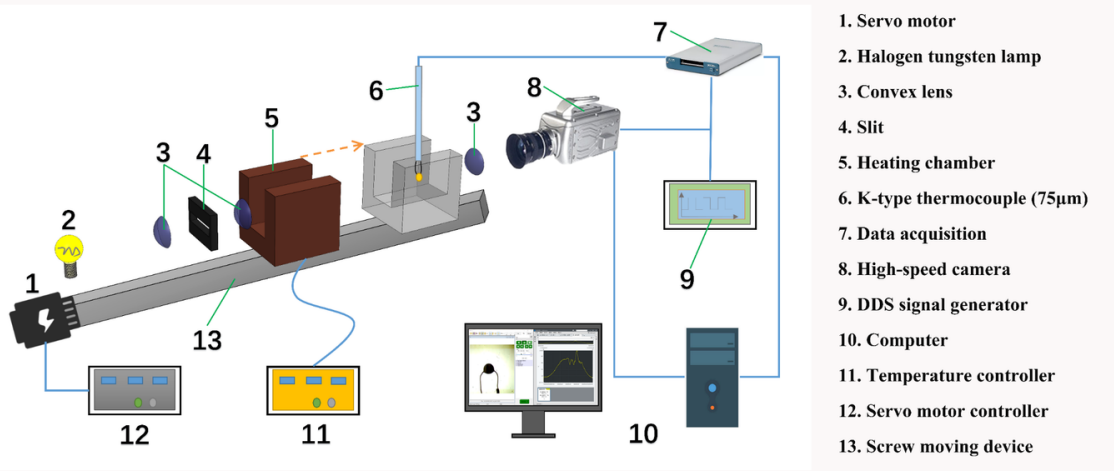


Figure 2 Schematic of the single droplet micro-explosion experiment with backlighting imaging.

The schematic of the shadowgraph imaging setup is shown in Figure 3. A 250W halogen tungsten lamp was chosen as the light source, and its light was concentrated through a projection lens to form a spot. Adjustment of the slit opening means that the spot size is just enough to pass through the slit. The purpose of the slit is to filter out stray light outside the spot and obtain an ideal point light source with a clear boundary and concentrated to a point to obtain the highest image quality ${ }^{41}$. Then, the light is converged into parallel rays by imaging lens 1 to eliminate the image distortion caused by non-parallel rays. Finally, parallel rays are focused by imaging lens 2 for high-speed camera imaging. The larger the magnification of imaging is, the closer the camera is to the object, so it is thus necessary to use imaging lens 2, which can keep the camera away from the high-temperature heating chamber to obtain a clear image with high magnification. According to the principle of convex lens imaging, the image obtained by a high-speed camera is an inverted real image.

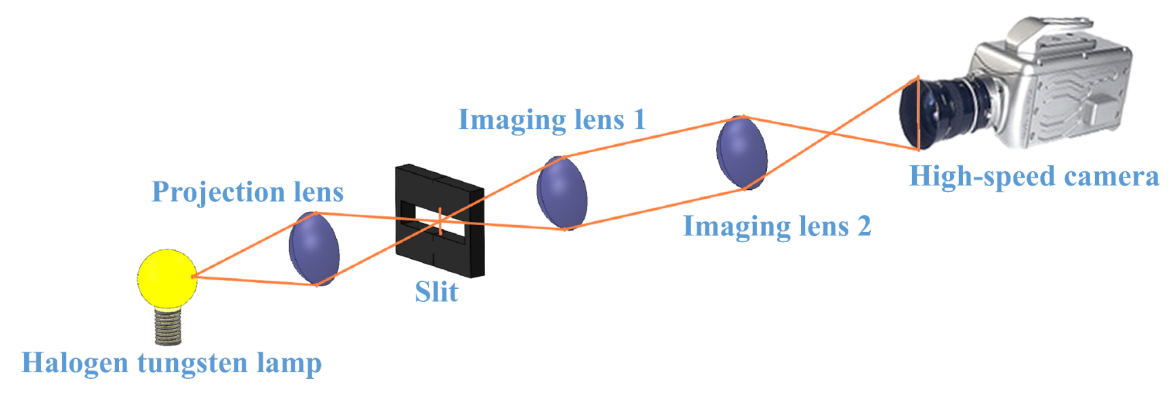

Figure 3 Schematic of the shadowgraph imaging setup

A single emulsion droplet was suspended on the junction of a K-type thermocouple (wire diameter $75 \mu \mathrm{m}$ ) by a $0.5 \mu \mathrm{L}$ micro-syringe. A heating chamber with a cross section fashioned like the letter $\mathrm{U}$ was first heated to the experimentally predetermined temperature which can be adjusted between 25 and 850 by the temperature controller. Then, the heating chamber was moved by a servo motor at a speed of $1 \mathrm{~m} / \mathrm{s}$ to the position where the droplet is located in the center of the heating chamber. Note, errors caused by the movement of the heating chamber can be eliminated by recording the time when the droplet reaches 30 as time 0. Simultaneously, a direct digital synthesis (DDS) signal generator generates a pulse signal that synchronously triggers the high-speed camera (Phantom V9.1) at the frame rates of 2000 frames per second with a long-distance microscope (Navitar 6010) at a resolution of $576 \times 576$ pixels and the data acquisition module (National Instruments 6361) at $4 \mathrm{kHz}$.

All experiments were carried out at the heating chamber temperature of 650 under atmospheric pressure, and they were repeated 10 times under each condition to reduce experimental errors.

\subsection{Measurement of particle size of the dispersed phase}

If the distance between two points is less than half of the wavelength of light, we will not be able to distinguish the two points through a microscope, which is called the Abbe limit ${ }^{42}$. Therefore, the particle size of emulsion with average less than $1 \mu \mathrm{m}$ of dispersed phase is generally characterized by dynamic light scattering (DLS) and transmission electron microscope (TEM). In this study, the particle size of dispersed phase was measured by DLS (NiComp380ZLS, PSS Company). Then, samples with an average particle diameter of less than 1 $\mu \mathrm{m}$ were measured again by TEM (JEM1400, JEOL) to verify the authenticity of particle size of dispersed phase. The Sauter mean diameters (SMD) of emulsion fuels were calculated by Eq. (1) according to the data of DLS.

$\mathrm{SMD}=\frac{\sum n_{i} D_{i}{ }^{3}}{\sum n_{i} D_{i}{ }^{2}}$ 


\subsection{Measurement of surface tension}

Measurement of surface tension of polymer solutions was made using a tensiometer (DCAT21, Dataphysics) that operates on the Wilhelmy plate method. It keeps the sample at a constant temperature $( \pm 0.1)$ through a circulating water bath. Then, the sample rose slowly until it came into contact with the plate. Finally, the force acting on a vertically immersed plate was measured to calculate the surface tension.

\subsection{Measurement of rheological properties}

Measurement of rheological properties of polymer solutions was made using a rotating rheometer (Physica MCR-101, Anton Paar). Using the double-gap cylinder assembly (DG26.7) in the MCR-101 rheometer, viscosity data can be obtained at shear rates between $10 \mathrm{~s}^{-1}$ and $3000 \mathrm{~s}^{-1}$, with the temperature kept constant at 25 by the built-in Peltier heating system.

\subsection{Measurement of thermogravimetric analysis}

Measurement of thermogravimetric analysis of polymer additives and surfactants was made using a simultaneous thermal analyzer (STA 449 F3, Netzsch Company). In the nitrogen atmosphere, the temperature rose from room temperature to 800 at a heating rate of $10 / \mathrm{min}$, and the instrument recorded the decomposition process of the above substances.

\section{Results and discussion}

\subsection{Particle size of dispersed phase}

The particle size distribution of dispersed water phase measured by DLS and the SMD calculated from it are shown in Figure 4. With the increase of XG addition, the particle size of dispersed water phase gradually decreased, while the trend of NPAM additive was opposite. As shown in Figure 5, TEM characterization was performed for each emulsion. 


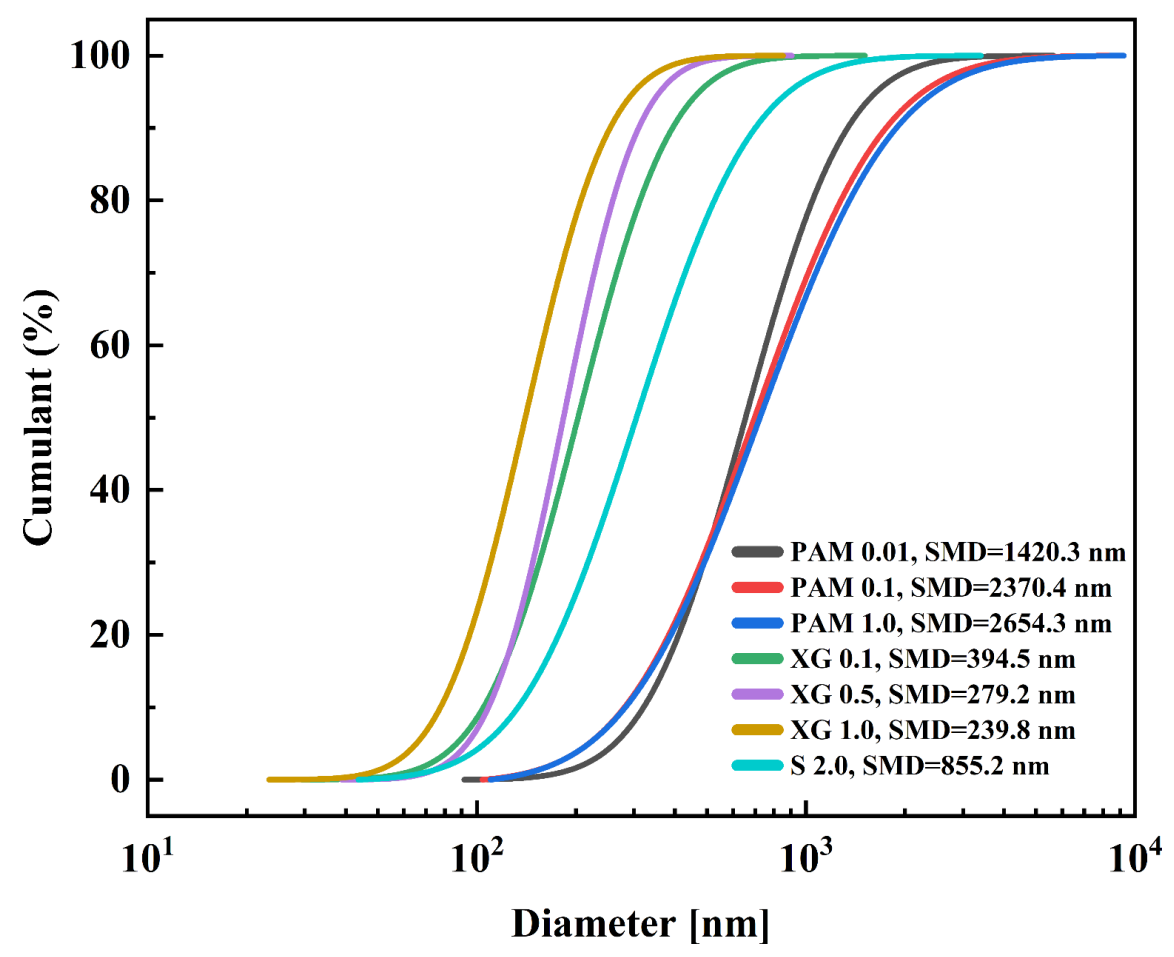

Figure 4 SMD and cumulative distribution of particle size of dispersed water phase for different types of emulsions (data from DLS)

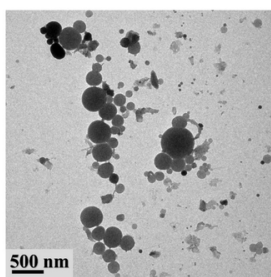

a

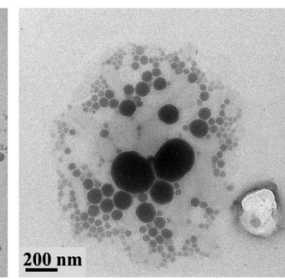

b

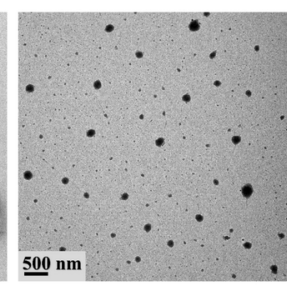

c
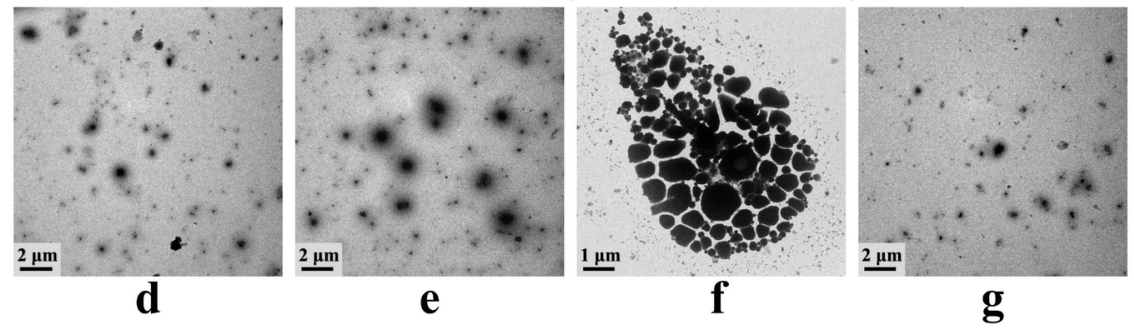

Figure 5 TEM images of various types of emulsions (a) XG0.1; (b) XG0.5; (c) XG1.0; (d) PAM0.01;

(e) PAM0.1; (f) PAM1.0; (g) S2.0 


\subsection{Surface tension}

The surface tension varies with the polymer concentration in water as shown in Figure 6 . The surface tension of NPAM solution decreased continuously from that of the solvent to the minimum asymptotic value of $39.45 \mathrm{mN} / \mathrm{m}$. Accordingly, XG solution also has the same trend, and its minimum asymptotic value is $57.79 \mathrm{mN} / \mathrm{m}$. Therefore, NPAM has higher surface activity than XG. Similar to the concept of critical micelle concentration (CMC), the concentration of the lower inflection point in the $\sigma$-c isotherm, that is, the point of transition to the asymptote of minimum surface tension, is often referred to as the critical polymer concentration (CPC) or critical cluster overlapping concentration $\left(\mathrm{C}^{*}\right)^{43,44}$. As seen in Figure. 6 , the critical polymer concentrations of NPAM and XG are estimated to be $10 \mathrm{~g} / \mathrm{m}^{3}$ and $50 \mathrm{~g} / \mathrm{m}^{3}$, respectively. In fact, the CPC and the size of the surface tension of solutions at different concentrations are the criteria for how much polymer is added to prepare the different types of emulsions shown in Table 2.
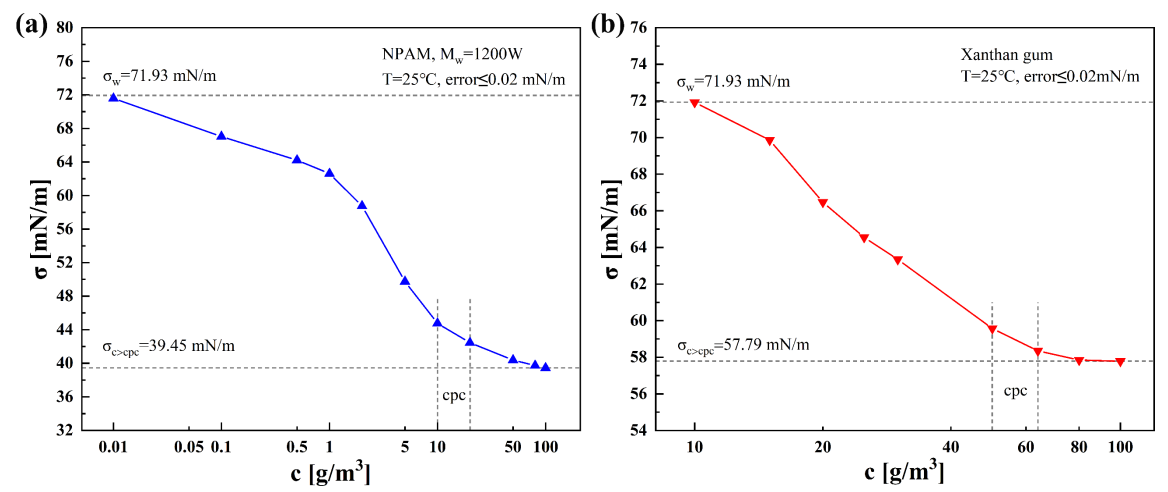

Figure 6 Trend of surface tension of polymer solution with polymer concentration (a) the trend
of NPAM; (b) the trend of XG

\subsection{Rheological properties}

Generally, aqueous solutions of NPAM and XG display viscous pseudoplastic behavior. Properties of this non-Newtonian fluid are shown in Figure. 7, which shows how the viscosity of NPAM and XG solutions varies with shear rate at different concentrations. It can be seen that the thickening of XG solutions is much better than that of NPAM solutions, especially at high concentrations. At low concentration $\left(1 \mathrm{~g} / \mathrm{m}^{3} \mathrm{and}\right.$ $10 \mathrm{~g} / \mathrm{m}^{3}$ ), NPAM solution rheology tends to be Newtonian, with a significantly higher viscosity than the solvent, and the pseudoplastic behavior only manifests at high concentration $\left(100 \mathrm{~g} / \mathrm{m}^{3}\right)$. In contrast, XG

manifests strong pseudoplasticity at all concentrations tested. Moreover, when the shear rate increases, the viscosity of XG solutions decreases faster than that of NPAM solutions. 


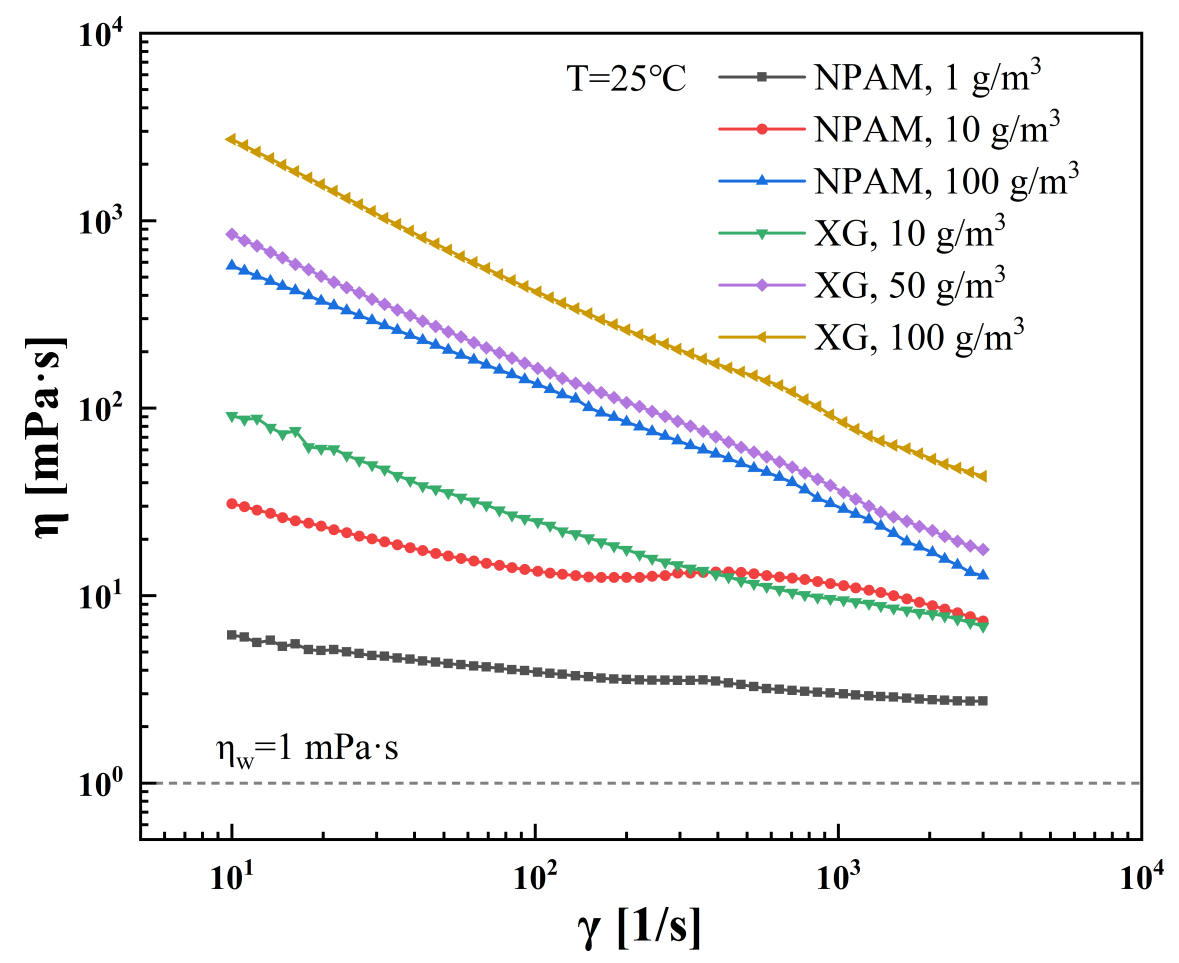

Figure 7 Viscosity trend of NPAM and XG aqueous solutions for different concentrations with shear rate

\subsection{Thermogravimetric analysis}

During thermogravimetric analysis, weight loss and temperature change during the process were recorded in thermogravimetric (TG) and derivative thermogravimetric (DTG) formats. The mass loss of polymer additives and surfactants during thermal decomposition as a function of pyrolysis temperature in inert environment at a heating rate of $10 / \mathrm{min}$ is shown in Figure. 8. It can be seen that the thermal decomposition temperatures of XG, NPAM and Span80 are much higher than 200. In addition, the temperature of the droplet is generally lower than 200 due to the vaporization process of the liquid phase in the micro-explosion process. In summary, it proves that all phenomena in the micro-explosion process have nothing to do with the pyrolysis of foreign additives (XG, NPAM, Span80). 
(a)

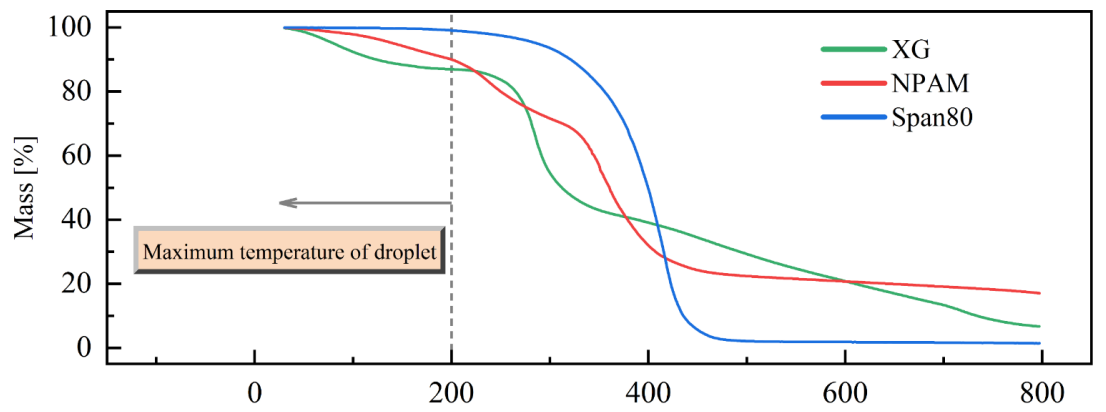

(b)

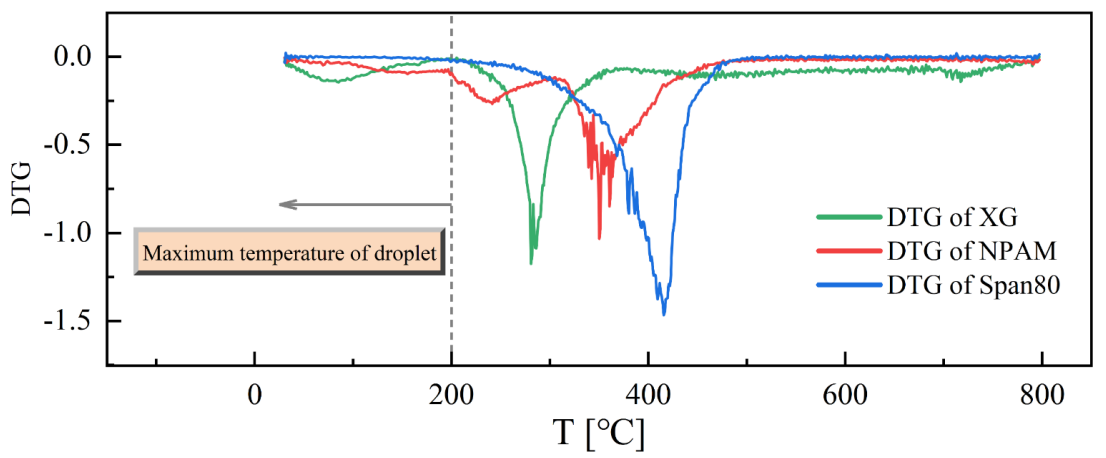

Figure 8 (a)TG and (b)DTG curve derived from the thermogravimetric analysis of XG, NPAM, and Span80

\subsection{Five forms of micro-explosions}

Generally, micro-explosion can be divided into "Optimal micro-explosion" and "Puff" 6,7,12,15-22 . However, with the addition of polymer additives, we found that micro-explosions take on five forms named "Optimal micro-explosion", "Big-ball", "High-frequency ejection", "Big-ball \& High-frequency ejection" and "Foam". Each of these five forms will be explained in the following sections.

(1) Optimal micro-explosion. As shown in Figure 9a (see Video S1 in the electronic Supporting information), the typical optimal micro-explosion is characterized by the vaporization of the water phase within $1 \mathrm{~ms}$ without any obvious expansion process of the droplet, and the whole droplet is shredded into aerosols. Optimal micro-explosion can tear droplets apart in an instant to produce an incalculable number of sibling droplets. It is therefore considered to be the optimal form of micro-explosion. As shown in Table 1, previous studies have shown that the optimal micro-explosion can only occur when the surfactant concentration is less than $2 \%$ and the particle size of the dispersed water phase is greater than $2 \mu \mathrm{m}$. This is because the necessary condition for the occurrence of optimal micro-explosion is to undergo the coalescence of dispersed water phase first ${ }^{17,23-25}$. However, high concentration of surfactant and relatively small particle size of dispersed water phase can hinder this coalescence process.

(2) Big-ball micro-explosion. As shown in Figure 9b (and see Video S2 in the electronic Supporting information), Big-ball micro-explosion is characterized by the droplet extremely expanding into a sphere with a diameter about 4 times that of the initial droplet. Subsequently, the liquid film consisting of the oil phase is torn, producing a large number of sibling droplets.

(3) High-frequency ejection (HE). As shown in Figure 9c (see Video S3 in the electronic Supporting information), High-frequency ejection is a phenomenon in which the droplet body has almost no obvious expansion and the sibling droplets are ejected from the droplet body at a continuous high frequency. 
(4) Big-ball \& High-frequency ejection $(\mathrm{B} \& \mathrm{H})$. As shown in Figure 9d (see Video S4 in the electronic Supporting information), the phenomenon of $\mathrm{B} \& \mathrm{H}$ is characterized by the droplet body expansion accompanied by a large number of ejections. However, compared with the Big-ball micro-explosion, it is not a regular sphere, but presents an irregular shape. And the size of the expansion is much smaller than the Big-ball micro-explosion.

(5) Foam. As shown in Figure 9e (see Video S5 in the electronic Supporting information), the Foam phenomenon is characterized by the simultaneous existence of multiple bubbles in the droplet body and the continuous breakage of bubbles, accompanied by the generation of new bubbles. In the whole process, the droplet body presents a form of foam. This may be because the strength of the gas-liquid interface film is too strong to coalesce between bubbles.

(a)

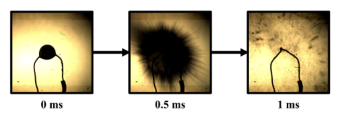

(b)

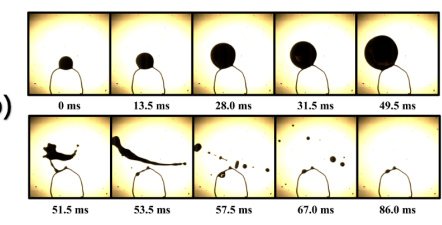

(c)

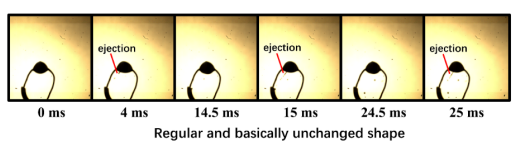

(d)

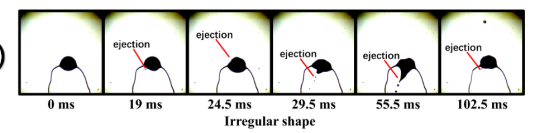

(e)

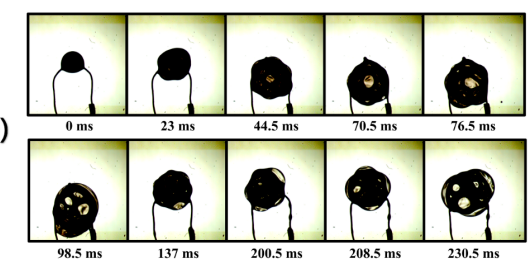

Figure 9 Evolution of micro-explosion time for various forms (a)Optimal micro-explosion; (b)Big-ball micro-explosion; (c)High-frequency ejection; (d)Big-ball \& High-frequency ejection; (e)Foam

In the following sections, according to the calculation method of micro-explosion intensity (see Model S1 in the electronic Supporting information), we will evaluate the atomization effect of five kinds of microexplosions $I_{i}$, the micro-explosion intensity $I_{m}$ and the atomization effect of micro-explosion $I_{i m}$ under each process condition. The atomization effects of five kinds of micro-explosion forms are therefore numerically quantified, allowing for more intuitive comparison between the atomization effects of various micro-explosion forms.

Evaluations of atomization effect for five kinds of micro-explosions are shown in Figure 10. The atomization effect factor $I_{i}$ of Foam is close to zero (see Video S5 in the electronic Supporting information). This is because in this form of micro-explosion, droplets not only expand slowly due to the slow rate of vaporization for the water phase, but the number of sibling droplets is also small. Therefore, this situation should be avoided in practical application. In addition, the atomization effect factor $I_{i}$ of Big-ball micro-explosion, HE micro-explosion and B\&H micro-explosion is in the same order of magnitude (see Video S2, Video S3 and Video S4 in the electronic Supporting information). Among them, the atomization effect factor $I_{i}$ of B\&H type micro-explosion is between that of Big-ball and HE micro-explosion. This difference may be caused by the fact that the ejection of $\mathrm{B} \& \mathrm{H}$ micro-explosion in the droplet expansion process hinders the droplet expansion process and reduces the micro-explosion intensity. If the Big-ball micro-explosion is like a balloon that keeps inflating, and eventually the liquid film formed by the oil phase reaches the limit that it can bear and is torn apart, then the $\mathrm{B} \& \mathrm{H}$ micro-explosion is like a needle sticking on the balloon in the process of inflating. Moreover, the atomization effect factor $I_{i}$ of Optimal micro-explosion is 3 orders of magnitude higher than that of other forms of micro-explosion (see Video S1 in the electronic Supporting information). 


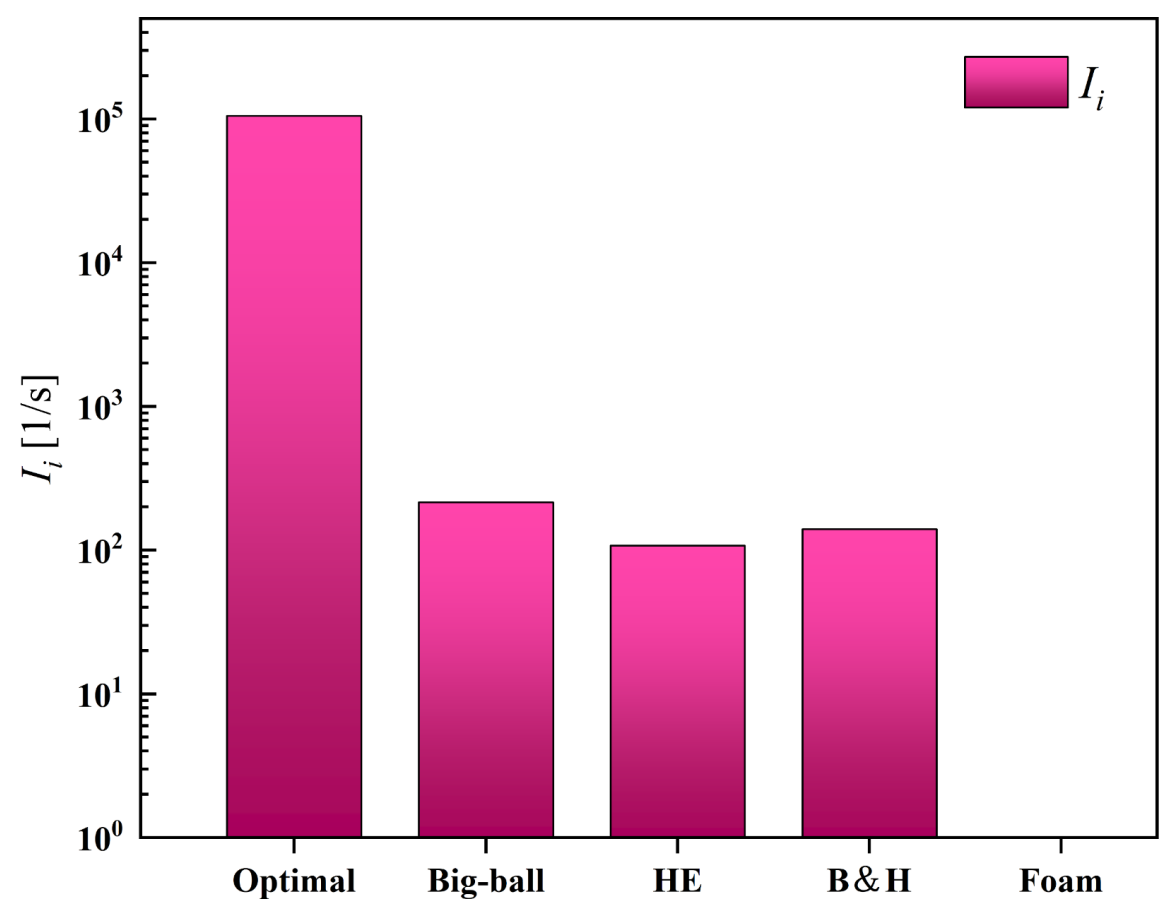

Figure 10 Evaluation of atomization effect for five kinds of micro-explosions

\subsection{Effect of polymer additives on micro-explosions}

The probability of various types of micro-explosions occurring in different types of emulsions is shown in Figure 11. In particular, since a droplet may switch between many types of micro-explosions during its lifetime, the sum of the probabilities of the various types of micro-explosions in a type of emulsion does not equal 100\%. As shown in Figure 11, PAM0.01, XG0.1 and S2.0 emulsions have similar probability distributions of micro-explosions in various forms. This indicates that the effect of polymer addition at low concentration $(<0.1 \%)$ on micro-explosion of emulsion is very limited. In addition, it can be seen from Figure11 that when XG and NPAM are added with a higher concentration, no Big-ball micro-explosion will occur, but the probability of $\mathrm{HE}$ and $\mathrm{B} \& \mathrm{H}$ type micro-explosion will be greatly increased. Among them, adding a higher concentration $(0.5 \%$ and $1.0 \%)$ of XG will also lead to optimal micro-explosion, and there is an extreme value $(0.5 \%)$ of XG addition that maximizes the probability of optimal micro-explosion. On the contrary, the addition of higher concentration of NPAM will make the droplet only B\&H type microexplosion, almost no other ones. In addition, Foam micro-explosion only appeared in XG1.0 emulsion with high concentration of XG. 


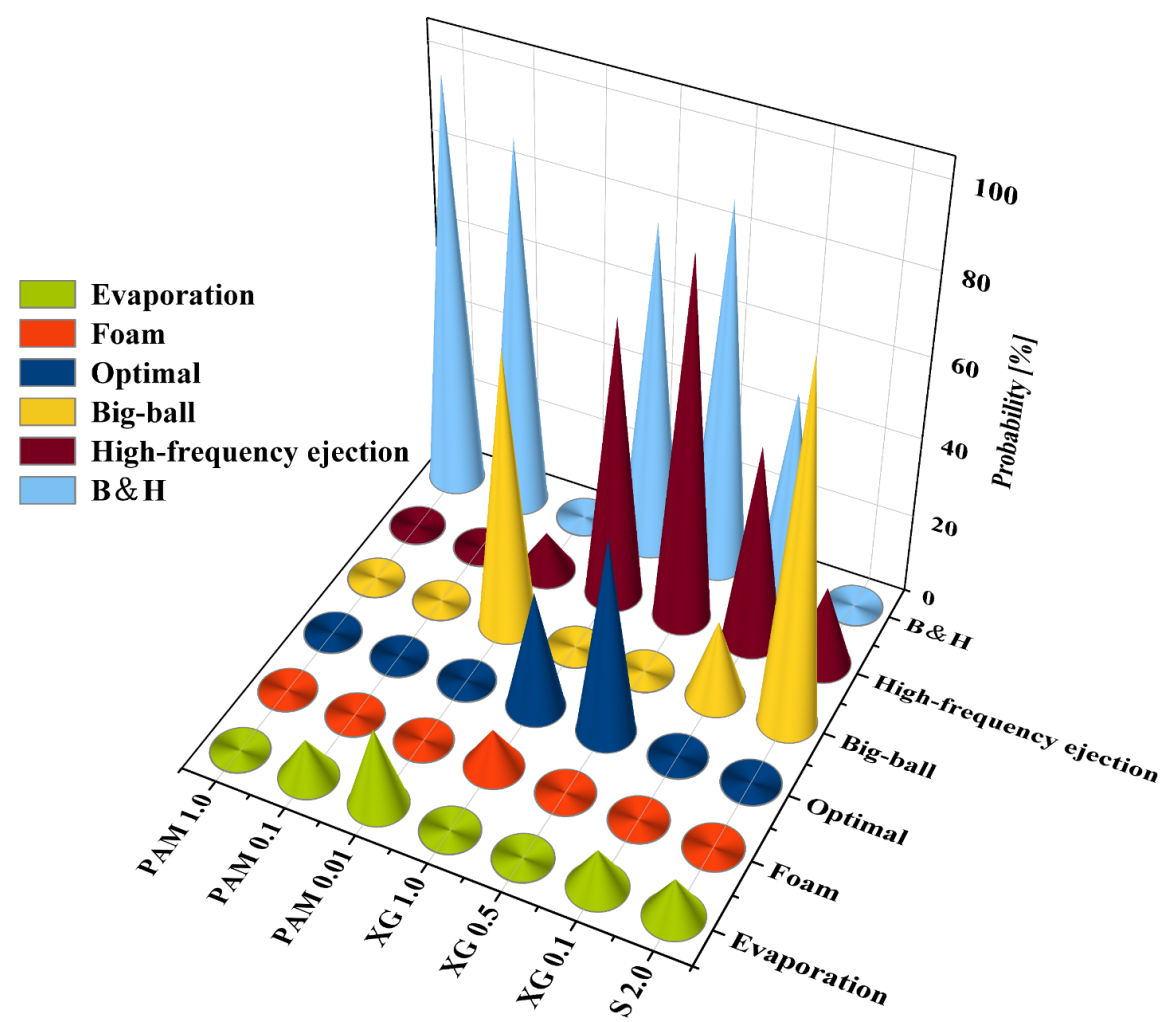

Figure 11 The probability of various types of micro-explosions occurring in different types of emulsions

Figure 12 shows the calculation results of average micro-explosion intensity factor $I_{m}$ and atomization effect factor $I_{i m}$ of different types of emulsions. It can be seen that the micro-explosion intensity factor and atomization effect factor of XG0.5, XG1.0, PAM0.1 and PAM1.0 emulsions are greatly increased compared with S2.0 emulsions. This indicates that the addition of high concentration polymer additives greatly improves the micro-explosion intensity and atomization effect. Besides, there is an extreme point in the amount of $\mathrm{XG}$, which results in the best micro-explosion intensity and atomization effect. As mentioned above, there is an extreme point in the amount of XG to lead to the maximum probability of optimal micro-explosion, and the optimal micro-explosion has a higher atomization effect than other forms of micro-explosion by 3 orders of magnitude. In contrast to XG, with increasing NPAM addition, the micro-explosion intensity factor will increase but the atomization effect factor will decrease. In addition, it was found that the strengthening effect of high concentration XG on micro-explosion was obviously better than that of NPAM. 


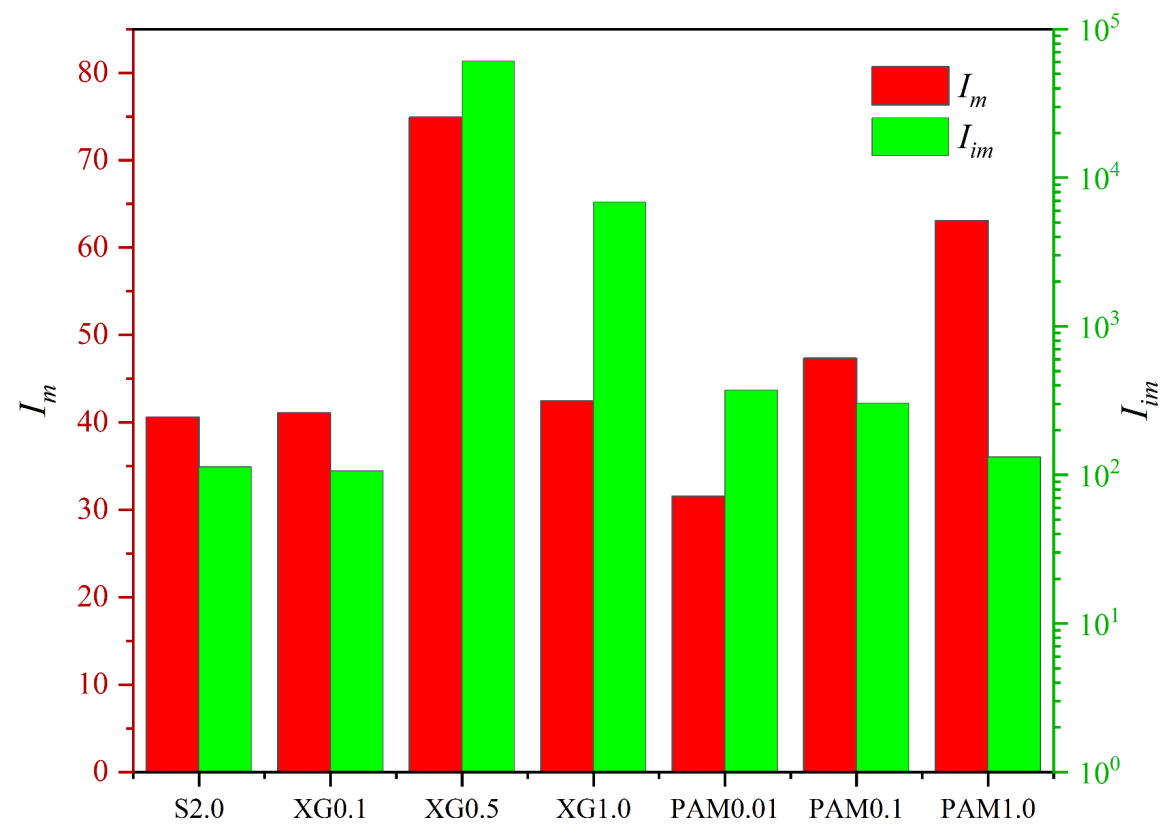

Figure 12 The calculated results of average micro-explosion intensity factor $I_{m}$ and atomization effect factor $I_{i m}$ for different types of emulsions

The data closest to the average micro-explosion intensity factor $I_{m}$ was selected as the representative to show the temperature evolution in the micro-explosion process, (see Figure S3 in the electronic Supporting information). The temperature data of the 10 experiment repeats for each emulsion were statistically analyzed. Then, the maximum temperature drop due to micro-explosion $\left(\Delta \mathrm{T}_{\max }\right)$, the initial temperature of microexplosion $\left(\mathrm{T}_{0}\right)$ and the maximum temperature of the droplet during micro-explosion $\left(\mathrm{T}_{\max }\right)$ were obtained. The results are shown in Figure13. Low concentration of polymer addition amount has little influence on $\Delta \mathrm{T}_{\max }, \mathrm{T}_{0}$ and $\mathrm{T}_{\max }$, in accordance with the results from micro-explosion intensity and micro-explosion probability of various forms. In addition, the amount of XG also has an extreme point, which maximized the values of $\Delta \mathrm{T}_{\max }, \mathrm{T}_{0}$ and $\mathrm{T}_{\max }$. Finally, the addition of NPAM at lower concentrations $(0.01 \%$ and $0.1 \%$ ) seems to have little effect on $\Delta \mathrm{T}_{\max }, \mathrm{T}_{0}$ and $\mathrm{T}_{\max }$. However, high concentration of NPAM $(1.0 \%)$ decreases $\Delta \mathrm{T}_{\max }, \mathrm{T}_{0}$ and $\mathrm{T}_{\max }$ values. In particular, the NPAM1.0 emulsion has a vaporization nucleation temperature even lower than the saturation temperature of water (100), that is, it may be in a supercooled boiling state. In this state, the oil phase temperature is much higher than the saturation temperature of water, but the water phase is still below the saturation temperature. This may be an important reason for the reduction of the atomization effect factor caused by the addition of high concentration NPAM. 


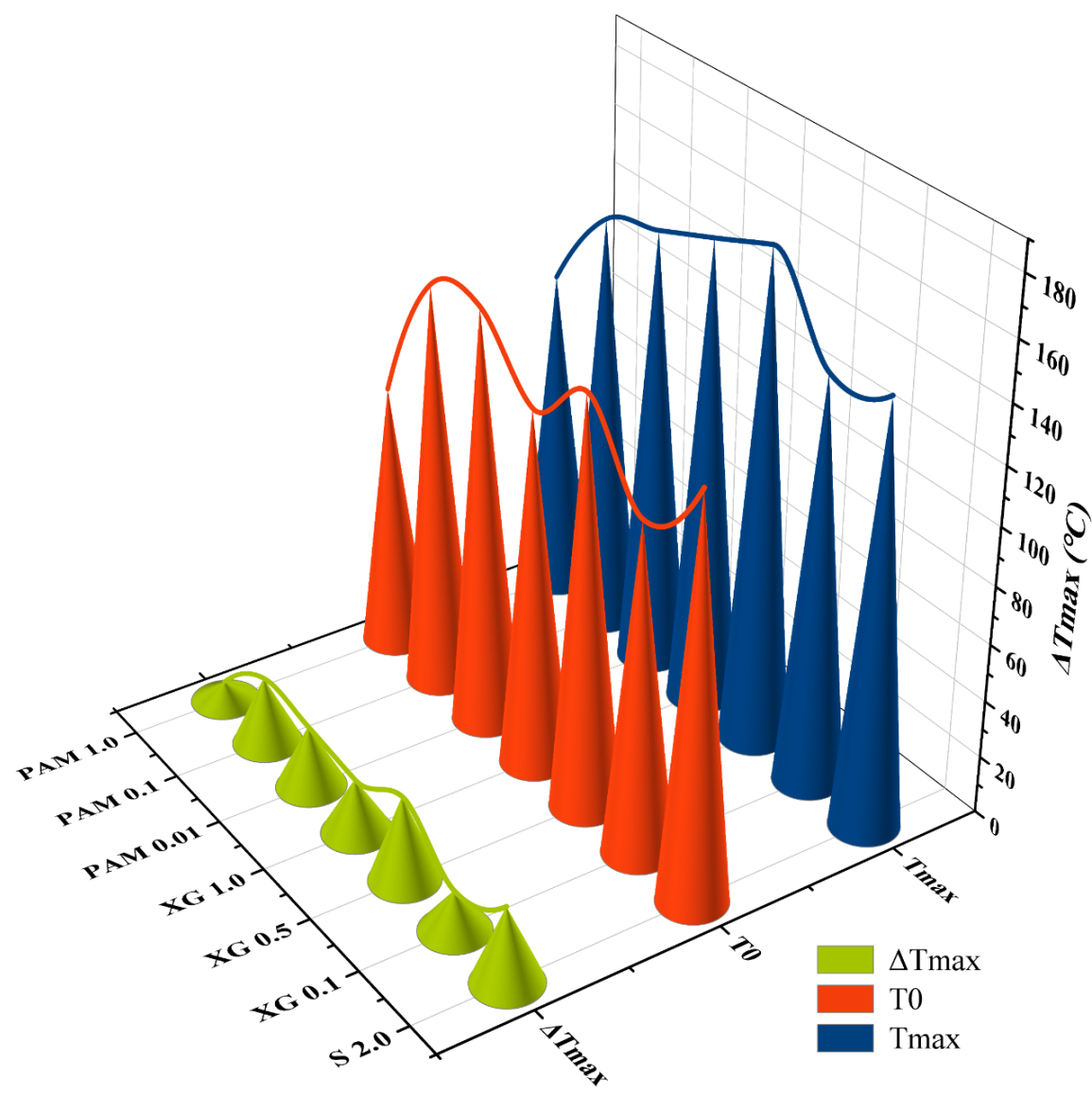

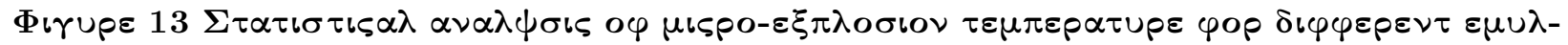

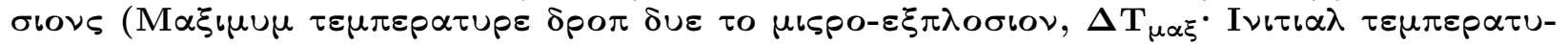

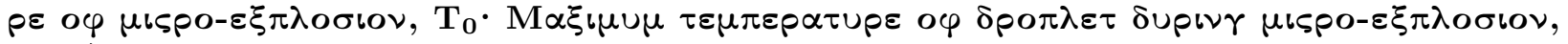
$\left.\mathbf{T}_{\mu \alpha \xi}\right)$

\subsection{Mechanism for effect of polymer additive on micro-explosion}

As shown in Eq. (2), for the formation of a bubble of radius $r$ in the liquid phase, the energy consumed is used to offset the specific free energy and the interface surface energy.

$E=\frac{4}{3} \pi r^{3} \rho_{g} \frac{i_{l-g} \Delta T_{S}}{T_{S}}+4 \pi r^{2} \sigma(2)$

where $r$ is the bubble radius, $\rho_{\gamma}$ is the density of the gas inside the bubble, $i_{l-g}$ is vaporization enthalpy, $\Delta T_{S}$ $=T_{0}-T_{S}$ is liquid superheat, $T_{S}$ is liquid saturation temperature and $\sigma$ is surface tension. By differentiating Eq. (2), Eq. (3) is obtained from $\left.\frac{\mathrm{dE}}{\mathrm{dr}}\right|_{r=r_{c}}=0$.

$r_{c}=\frac{2 \sigma T_{S}}{\rho_{g} i_{l-g} \Delta T_{S}}$

where $r_{c}$ is critical bubble radius. In other words, all bubbles with diameters $r<r_{c}$ will gradually shrink and disappear, and only those with diameters $r$ [?] $r_{c}$ can exist and grow. Under experimental conditions, $\rho_{\gamma}, i_{l-g}$ and $T_{S}$ can all be regarded as constants. Therefore, surface tension becomes the decisive factor to determine the micro-explosion intensity. On the other hand, previous studies have shown that at the oil-water interface, due to the different relationship between surface tension and interfacial tension, there are three possible scenarios where bubbles form ${ }^{45,46}$, as shown in Figure 14. For the W/O emulsion prepared 
from n-hexadecane, bubbles are obviously located in the oil phase due to the low molecular weight of nhexadecane and the addition of surfactants in the oil phase, as shown in Figure 14c. In other words, the bubbles in the $\mathrm{W} / \mathrm{O}$ emulsion are in the oil phase with relatively low surface tension rather than in the water phase with higher surface tension. This explains why the micro-explosion effect of emulsions prepared with high concentrations of oil-soluble surfactants was not strong in previous studies ${ }^{15-17}$.

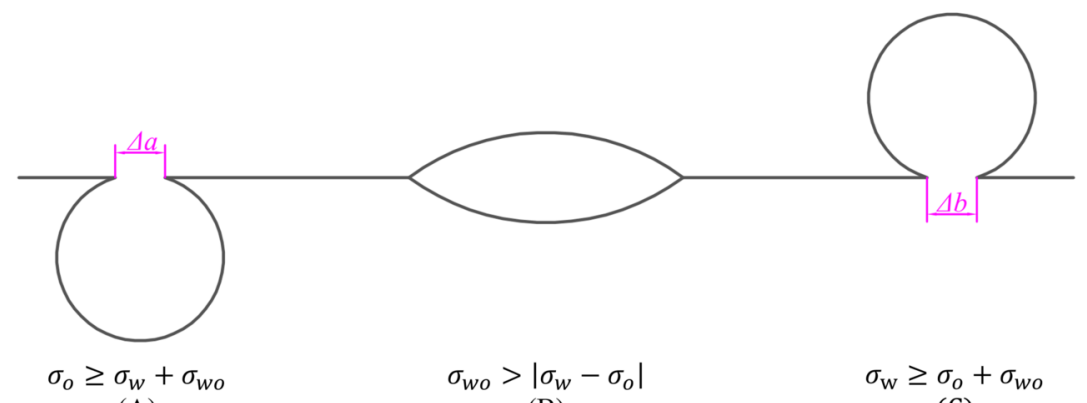

(A)

(B)

(C)

Figure 14 The different positions of bubbles at the oil-water interface caused by the different relationship between surface tension and interfacial tension

To sum up, there are two ways to enhance the micro-explosion phenomenon of $\mathrm{W} / \mathrm{O}$ emulsions: one is to reduce the amount of surfactant used ${ }^{15,17,21,22,39,40}$; the other is to let bubbles form in the water phase with relatively high surface tension as much as possible. The addition of water-soluble polymers to enhance the micro-explosion phenomenon falls into the latter category. First of all, polymer additives adsorb at the oil-water interface due to their surface activity. Then, their high viscosity prevents bubbles from migrating to the oil phase with low surface tension. Finally, once the temperature of the water phase is high enough, bubbles begin to form in large numbers and migrate. Due to the pseudoplasticity of the polymer solution, the viscosity of the solution begins to drop, which causes the bubbles to migrate at a faster rate, and then the greater shear rate causes the viscosity of the solution to drop further, and so on, creating a snowball effect that allows the catastrophic micro-explosion to occur.

However, the addition of XG has a stimulant effect on micro-explosion, but NPAM does not (Figure 11 and Figure 12). This may be due to the high surface activity of NPAM (Figure 6). This explanation was validated by comparing the micro-explosion effects of XG0.5 and PAM1.0 emulsions with similar viscosity of polymer solutions (Figure 7).

\section{ConclusionS}

In this study, the effect of XG and NPAM on the micro-explosion for W/O emulsions were studied to solve the contradiction between the particle size of dispersed water phase and the intensity of micro-explosion. The results show that the optimal micro-explosion is successfully achieved in the emulsion with high concentration $(2 \%)$ of surfactant and small diameter $(\mathrm{SMD}=239.8 \mathrm{~nm})$ of dispersed water phase. After the addition of polymer additives, the micro-explosion had more forms, namely "Optimal micro-explosion", "Big-ball", "High-frequency ejection", "Big-ball \& High-frequency ejection" and "Foam".

Furthermore, the results show that $0.5 \%$ and $1 \%$ XG can promote the optimal micro-explosion of stable emulsion, but the probability of optimal micro-explosion in the former $(60 \%)$ is higher than that in the latter $(30 \%)$.. The reasons for this phenomenon could be the low surface activity, strong thickening and pseudoplasticity of XG solution. Moreover, the addition of NPAM did not promote micro-explosion because of its strong surface activity. 
Finally, previous studies ${ }^{17,23-25}$ have suggested that oil-soluble surfactants affect micro-explosion by affecting the coalescence of dispersed water phase in $\mathrm{W} / \mathrm{O}$ emulsions prepared by oil-soluble surfactants. Combining with findings from previous studies, we propose a new mechanism, which is that the relationship between surface tension and interfacial tension affects the position of bubbles and thus the micro-explosion. This mechanism differs from previous studies in that oil-soluble surfactants not only affect the coalescence of dispersed water phase, but also affect the bubble nucleation of water phase.

In conclusion, this work has provided useful insights into solving the contradiction between emulsion stability and micro-explosion intensity. This provides a new idea for further research to achieve the ultimate goal of optimal micro-explosion in microemulsion based hybrid biofuels. In addition, this enhanced atomization mechanism can be applied to the preparation of nanoparticles during FSP process, which may improve the particle size distribution and greatly enhance the production capacity of nanoparticles.

\section{Acknowledgement}

The authors would like to thank the Sinopec Innovation Foundation for funding this project under the grant number 120022. The authors thank the Research Center of Analysis and Test of East China University of Science and Technology for the characterization of TEM, and Sinopec Qilu Company for providing technological supports.

\section{CONFLICT OF INTEREST}

We declare that we have no financial and personal relationships with other people or organizations that can inappropriately influence our work, there is no professional or other personal interest of any nature or kind in any product, service and/or company that could be construed as influencing our manuscript.

The authors declare no competing financial interest.

\section{SUPPORTING INFORMATION}

Make a list of the supporting documents;

\begin{tabular}{ll}
\hline Filename & Description \\
\hline Data S1 & Figure S3 Supplementary Information and Model S1 Supplementary Information \\
Video S1, Optimal micro-explosion & Video S1 Supplementary Information \\
Video S2, Big-ball micro-explosion & Video S2 Supplementary Information \\
Video S3, High-frequency ejection & Video S3 Supplementary Information \\
Video S4, B\&H & Video S4 Supplementary Information \\
Video S5, Foam & Video S5 Supplementary Information \\
\hline
\end{tabular}

Using the instruction or a published paper on $\mathrm{AiChE}$ as a model...

\section{References}

1. Carvajal L, Buitrago-Sierra R, Santamaria A, Angel S, Wiggers H, Gallego J. Effect of Spray Parameters in a Spray Flame Reactor During FexOy Nanoparticles Synthesis. Journal of Thermal Spray Technology . Feb 2020;29(3):368-383. doi:10.1007/s11666-020-00991-1

2. Wang ZW, Shi SG, Huang S, et al. Effects of water content on evaporation and combustion characteristics of water emulsified diesel spray. Applied Energy . Sep 2018;226:397-407. doi:10.1016/j.apenergy.2018.06.023

3. Yan YQ, Chen LM, Xu JS, Ren MN, Da JW, Cao FH. The micro-explosion strength of emulsified heavy oil droplets in catalytic cracking process. Chemical Engineering and Processing-Process Intensification. Nov 2016;109:90-96. doi:10.1016/j.cep.2016.08.020 
4. Li H, Rosebrock CD, Riefler N, Wriedt T, Maedler L. Experimental investigation on microexplosion of single isolated burning droplets containing titanium tetraisopropoxide for nanoparticle production.Proceedings of the Combustion Institute . 2017;36(1):1011-1018. doi:10.1016/j.proci.2016.09.017

5. Isakov I, Faber H, Grell M, et al. Exploring the Leidenfrost Effect for the Deposition of High-Quality In2O3 Layers via Spray Pyrolysis at Low Temperatures and Their Application in High Electron Mobility Transistors. Advanced Functional Materials . Jun 2017;27(22)1606407. doi:10.1002/adfm.201606407

6. Antonov D, Piskunov M, Strizhak P, Tarlet D, Bellettre J. Dispersed phase structure and microexplosion behavior under different schemes of water-fuel droplets heating. Fuel . Jan 2020;259116241. doi:10.1016/j.fuel.2019.116241

7. Shlegel N, Strizhak P, Tarlet D, Bellettre J. Comparing the integral characteristics of secondary droplet atomization under different situations. International Communications in Heat and Mass Transfer. Nov 2019;108104329. doi:10.1016/j.icheatmasstransfer.2019.104329

8. Yan YQ, Gonzalez-Cortes S, Yao BZ, et al. The decarbonization of coal tar via microwave-initiated catalytic deep dehydrogenation. Fuel . May 2020;268117332. doi:10.1016/j.fuel.2020.117332

9. Yan YQ, Gonzalez-Cortes S, AlMegren H, Edwards PP, Cao FH, Xiao TC. Hydrogen production from crude oil with fine iron particles through microwave-initiated catalytic dehydrogenation promoted by emulsified feed. International Journal of Hydrogen Energy . Dec 2018;43(52):23201-23208. doi:10.1016/j.ijhydene.2018.10.141

10. Taniguchi I, Tussupbayev R. Synthesis of LiFePO4/C nanocomposites by a novel process and their electrochemical properties. Chemical Engineering Journal . Jun 2012;192:334-342. doi:10.1016/j.cej.2012.03.072

11. Song SA, Jung KY, Park SB. Preparation of Y2O3 Particles by Flame Spray Pyrolysis with Emulsion. Langmuir . Mar 2009;25(6):3402-3406. doi:10.1021/la8035924

12. Strizhak P, Volkov R, Moussa O, Tarlet D, Bellettre J. Child droplets from micro-explosion of emulsion and immiscible two-component droplets. Int J Heat Mass Transf . Apr 2021;169120931. doi:10.1016/j.ijheatmasstransfer.2021.120931

13. Lyu SJ, Tan HS, Wakata Y, et al. On explosive boiling of a multicomponent Leidenfrost drop. Article. Proc Natl Acad Sci U S A . Jan 2021;118(2):6. e2016107118. doi:10.1073/pnas.2016107118

14. Strizhak P, Volkov R, Moussa O, Tarlet D, Bellettre J. Measuring temperature of emulsion and immiscible two-component drops until micro-explosion using two-color LIF. Int $J$ Heat Mass Transf . Dec 2020;163120505. doi:10.1016/j.ijheatmasstransfer.2020.120505

15. Califano V, Calabria R, Massoli P. Experimental evaluation of the effect of emulsion stability on microexplosion phenomena for water-in-oil emulsions. Fuel . Jan 2014;117:87-94. doi:10.1016/j.fuel.2013.08.073

16. Melo-Espinosa EA, Bellettre J, Tarlet D, Montillet A, Piloto-Rodriguez R, Verhelst S. Experimental investigation of emulsified fuels produced with a micro-channel emulsifier: Puffing and micro-explosion analyses. Fuel . May 2018;219:320-330. doi:10.1016/j.fuel.2018.01.103

17. Shen SQ, Sun K, Che ZZ, Wang TY, Jia M, Cai JQ. Mechanism of micro-explosion of water-inoil emulsified fuel droplet and its effect on soot generation. Article. Energy . Jan 2020;191:9. 116488. doi:10.1016/j.energy.2019.116488

18. Antonov DV, Piskunov MV, Strizhak PA. Breakup and explosion of droplets of two immiscible fluids and emulsions. International Journal of Thermal Sciences . Aug 2019;142:30-41. doi:10.1016/j.ijthermalsci.2019.04.011

19. Watanabe H, Suzuki Y, Harada T, Matsushita Y, Aoki H, Miura T. An experimental investigation of the breakup characteristics of secondary atomization of emulsified fuel droplet. Energy . Feb 2010;35(2):806-813. doi:10.1016/j.energy.2009.08.021 
20. Antonov DV, Kuznetsov GV, Strizhak PA, Fedorenko RM. Micro-explosion of droplets containing liquids with different viscosity, interfacial and surface tension. Article. Chem Eng Res Des. Jun 2020;158:129-147. doi:10.1016/j.cherd.2020.03.029

21. Tarlet D, Mura E, Josset C, Bellettre J, Allouis C, Massoli P. Distribution of thermal energy of child-droplets issued from an optimal micro-explosion. Int $J$ Heat Mass Transf . 2014;77:1043-1054. doi:10.1016/j.ijheatmasstransfer.2014.06.054

22. Tarlet D, Allouis C, Bellettre J. The balance between surface and kinetic energies within an optimal micro-explosion. International Journal of Thermal Sciences . Sep 2016;107:179-183. doi:10.1016/j.ijthermalsci.2016.04.008

23. Tarlet D, Josset C, Bellettre J. Comparison between unique and coalesced water drops in microexplosions scanned by differential calorimetry. Int $J$ Heat Mass Transf . Apr 2016;95:689-692. doi:10.1016/j.ijheatmasstransfer.2015.12.054

24. Mura E, Josset C, Loubar K, Bellettre J, Massoli P. Experimental study of the water in oil emulsions features by differential scanning calorimetry analysis. Applied Energy . Sep 2012;97:834-840. doi:10.1016/j.apenergy.2011.12.095

25. Suzuki Y, Harada T, Watanabe H, et al. Visualization of aggregation process of dispersed water droplets and the effect of aggregation on secondary atomization of emulsified fuel droplets. Proceedings of the Combustion Institute . 2011/01/01/ 2011;33(2):2063-2070. doi:https://doi.org/10.1016/j.proci.2010.05.115

26. Ravera F, Dziza K, Santini E, Cristofolini L, Liggieri L. Emulsification and emulsion stability: The role of the interfacial properties. Advances in Colloid and Interface Science. Feb 2021;288102344. doi:10.1016/j.cis.2020.102344

27. Chang YC, Lee WJ, Yang HH, et al. Reducing Emissions of Persistent Organic Pollutants from a Diesel Engine by Fueling with Water-Containing Butanol Diesel Blends. Environmental Science 83 Technology . May 2014;48(10):6010-6018. doi:10.1021/es405278w

28. Teixeira AR, Hermann RJ, Kruger JS, et al. Microexplosions in the Upgrading of Biomass-Derived Pyrolysis Oils and the Effects of Simple Fuel Processing. Acs Sustainable Chemistry \& Engineering . Mar 2013;1(3):341-348. doi:10.1021/sc300148b

29. Kumar H, Sarma AK, Kumar P. A comprehensive review on preparation, characterization, and combustion characteristics of microemulsion based hybrid biofuels. Renewable 83 Sustainable Energy Reviews . Jan 2020;117109498. doi:10.1016/j.rser.2019.109498

30. Meng KS, Fu W, Lei YY, Zhao DM, Lin QZ, Wang GF. Study on micro-explosion intensity characteristics of biodiesel, RP-3 and ethanol mixed droplets. Fuel . Nov 2019;256115942. doi:10.1016/j.fuel.2019.115942

31. Okazawa T, Bron J. On thermodynamically stable emulsions. I. Thermodynamic background. J Colloid Interface Sci (USA) . 15 1979;69(1):86-96. doi:10.1016/0021-9797(79)90083-3

32. Zhao YL, Liu JL, Chen Z, Zhu XM, Moller M. Hybrid nanostructured particles via surfactant-free double miniemulsion polymerization. Nature Communications . May 2018;91918. doi:10.1038/s41467-018-04320-7

33. Wasekar VM, Manglik RM. A review of enhanced heat transfer in nucleate pool boiling of aqueous surfactant and polymeric solutions.Journal of Enhanced Heat Transfer . 1999;6(2-4):135-150. doi:10.1615/JEnhHeatTransf.v6.i2-4.70

34. Athavale AD, Manglik RM, Jog MA. An experimental investigation of nucleate pool boiling in aqueous solutions of a polymer. Aiche Journal . Mar 2012;58(3):668-677. doi:10.1002/aic.12616

35. Cheng LX, Mewes D, Luke A. Boiling phenomena with surfactants and polymeric additives: A state-of-the-art review. Int J Heat Mass Transf . Jul 2007;50(13-14):2744-2771. doi:10.1016/j.ijheatmasstransfer.2006.11.016 
36. Manglik RM, Athavale AD. Pseudoplasticity and Dynamic Interfacial Tension Relaxation Effects on Nucleate Pool Boiling in Aqueous Polymeric Liquids. Journal of Heat Transfer-Transactions of the Asme . May 2019;141(5)051502. doi:10.1115/1.4042699

37. Kotchaphakdee P, Williams MC. Enhancement of nucleate pool boiling with polymeric additives. Int $J$ Heat Mass Transf (UK) . May 1970;13(5):835-848. doi:10.1016/0017-9310(70)90129-8

38. Faik AMD, Zhang Y. Multicomponent fuel droplet combustion investigation using magnified high speed backlighting and shadowgraph imaging. Fuel . Jun 2018;221:89-109. doi:10.1016/j.fuel.2018.02.054

39. Mura E, Josset C, Loubar K, Huchet G, Bellettre J. EFFECT OF DISPERSED WATER DROPLET SIZE IN MICROEXPLOSION PHENOMENON FOR WATER IN OIL EMULSION. Atomization and Sprays . 2011-01-25 2010;20(9):791-799. doi:10.1615/AtomizSpr.v20.i9.40

40. Cen CZ, Wu H, Lee CF, Fan LJ, Liu FS. Experimental investigation on the sputtering and microexplosion of emulsion fuel droplets during impact on a heated surface. Article. International Journal of Heat and Mass Transfer. Apr 2019;132:130-137. doi:10.1016/j.ijheatmasstransfer.2018.12.007

41. Settles, G. S. Schlieren and Shadowgraph Techniques . Experimental Fluid Mechanics. Springer, Berlin, Heidelberg; 2001:XVIII, 376.

42. Jung YS, Kim M, Shi Y, Xi YG, Kim HK. A slanted-nanoaperture metal lens: subdiffraction-limited focusing of light in the intermediate field region. Nano Convergence . Nov 2018;533. doi:10.1186/s40580018-0165-y

43. Tam KC, Ng WK, Jenkins RD. Rheological properties of hydrophobically modified polyelectrolyte systems: Concentration effects. Journal of Applied Polymer Science . Dec 2006;102(6):5166-5173. doi:10.1002/app.24716

44. Wang YX, Fu JX, Liu MJ, Fu Q, Zhang J. Understanding the effect of chain entanglement state on melt crystallization of the polymer freeze-extracted from solution: The role of critical overlap concentration. Polymer. Sep 2019;178121588. doi:10.1016/j.polymer.2019.121588

45. Edrisi A, Dadvar M, Dabir B. A novel experimental procedure to measure interfacial tension based on dynamic behavior of rising bubble through interface of two immiscible liquids. Chemical Engineering Science . Feb 2021;231116255. doi:10.1016/j.ces.2020.116255

46. Jarvis TJ, Donohue MD, Katz JL. Bubble nucleation mechanisms of liquid droplets superheated in other liquids. J Colloid Interface Sci (USA) . Feb. 1975;50(2):359-368. doi:10.1016/0021-9797(75)90240-4 